\title{
Adverse Effect of Nonylphenol on the Reproductive System in F1 Male Mice: A Subchronic Low-Dose Exposure Model
}

\author{
Yong-Bin Kim¹, Yong-Pil Cheon², and `Sung-Ho Lee ${ }^{1}$ \\ ${ }^{1}$ Dept. of Biotechnology, Sangmyung University, Seoul 03016, Korea \\ ${ }^{2}$ Division of Developmental Biology and Physiology, School of Biological Sciences and Chemistry, \\ Sungshin University, Seoul 02844, Korea
}

\begin{abstract}
Nonylphenols (NPs) are widely used industrial materials, and are considered as potent endocrine disrupting chemical. Present study was undertaken to clarify the effect of subchronic low-dose NP exposure to F1 generation male mice. Mice were divided into 2 groups; (1) CON, control animals and (2) NP-50 (50 $\mu \mathrm{g} / \mathrm{L}$ ), animals were treated with NP via drinking water. NP exposures were continuously conducted from parental pre-mating period until the postnatal day (PND) 55 of F1 offsprings. Mice were sacrificed on PND 55 and the tissue weights were measured. The initial body weights (at PND 21) and terminal body weights (PND 55) of the NP-50 animals were significantly lower than those of control animals $(p<0.05)$. NP exposure induced a significant increase in the absolute weight of the testes $(p<0.05)$. Conversely, the NP exposure caused significant decrease in the absolute weights of the epididymis $(p<0.01)$, prostate $(p<0.05)$ and seminal vesicle $(p<0.05)$. Histopathological studies revealed that NP-treated animals exerted decreased seminiferous tubule diameters, reduced luminal area, and lower number of germ cells. Also some sloughing morphologies in the tubules were observed. In the caudal epididymis, fewer mature sperms and swollen epithelial cells were found in the NP-treated group. Our results confirmed that the subchronic low-dose NP exposure altered some male parameters and induced histopathological abnormalities in testis and epididymis of F1 mice. Since the NP dose used in this study is close to the average human daily NP exposure, our results could provide practically meaningful understanding of adverse effect of EDC in human.
\end{abstract}

Key words : Nonylphenol, F1 generation, Reproductive system, Histopathology

\section{INTRODUCTION}

Nonylphenol (NP), a subset of alkylpenol ethoxylates, is widely used as surfactant in the manufacturing industry and is present in detergents, paints, pesticides, personal care products, and plastics (de Weert et al., 2008). Since the original findings that NP has the estrogenic activity (Soto et al., 1991), previous studies demonstrated and suggested that NP was an endocrine disrupting chemical
(EDC) and could interfere with reproductive system in rodents (Nagao et al., 2001; Gong et al., 2009; Mehranjani et al., 2009; Uguz et al., 2009; Aly et al., 2012; Lu et al., 2014). In human, presence of NP and its metabolites in several tissues and blood is evident (Muncke, 2009; Huang et al., 2016; Acir \& Guenther, 2018). So it is certainly possible that human exposure to NP could induce reproductive toxicity as found in the rodent studies. Indeed, possible detrimental effects of NP on male fertility were systemati-

Manuscript received April 9, 2019, Received in revised form April 21, 2019, Accepted May 2, 2019

${ }^{\dagger}$ Corresponding Author : Sung-Ho Lee , Ph.D., Dept. of Biotechnology, Sangmyung University, Seoul 03016, Korea. Tel: +82-2-2287-5139, Fax: +82-22287-0070, E-mail: shlee@smu.ac.kr

This is an Open Access article distributed under the terms of the Creative Commons Attribution Non-Commercial License (http:// creative-commons.org/licenses/by-nc/3.0) which permits unrestricted non-commercial use, distribution, and reproduction in any medium, provided the original work is properly cited. 
cally documented in recent review studies (Noorimotlagh et al., 2017; Noorimotlagh et al., 2018). To confirm the adverse effects of NP on human, however, the low-dose tests that reflect the levels in range similar to those found in human bodies should take precedence. In addition, most of NP exposure occurs in living environment, so relatively long-term exposure via drinking water is suitable for simulating routine human exposure.

Present study was undertaken to clarify the effect of subchronic low-dose NP exposure to F1 generation male mice. To fulfill this goal, we employed the Organization for Economic Cooperation and Development (OECD) test guideline 443, an 'extended one-generation reproductive toxicity study'. The dose (50 $\mu \mathrm{g} / \mathrm{L})$ and delivery method (via drinking water) were chosen based on the previous studies that demonstrated the adverse effects on reproductive organs in mice (Kyselova et al., 2003; Cha et al., 2017).

\section{MATERIALS AND METHODS}

\section{Animals}

ICR mice were provided by DBL (Chungcheongbuk-do, Korea) and reared in Sangmyung University animal facility under photoperiods of $12 \mathrm{~h}$ light/dark with lights on at 7 $\mathrm{AM}$ and constant temperature of $21-23^{\circ} \mathrm{C}$. Food and tap water were supplied ad libitum. The animal protocols were approved by the Animal Care and Use Committees at Sangmyung University (approval number R-1601-1). All the animals received human care in accordance with the guides for animal experiments of the Association for Assessment and Accreditation of Laboratory Animal Care (AAALAC).

\section{Treatments and tissue preparations}

After acclimation, breeding pairs of mice were divided into 2 groups; (1) Control (CTL), supplied tap water, and (2) NP-50, treated with low-dose NP (50 $\mu \mathrm{g} / \mathrm{L}$; Sigma, USA) via drinking water. The parental generation mice had pre-mating period for 2 weeks. After pre-mating period, female and male mice were placed in the breeding cage until a vaginal plug of female mice was observed. The animals were treated with NP from pre-mating period to weaning of offsprings (F1). Then F1 generation mice were weaned at postnatal day (PND) 21 and consistently treated with the NP until sacrifice. Anogenital distance (AGD) were measured with a digital caliper on PND 35, 40, 45, 50, and 55. Animals were sacrificed at PND 55, and sample collections were done between 18:00-19:00 pm. The weights of reproductive tissues (testis, epididymis, seminal vesicle and prostate) were measured. Tissues were fixed in paraformaldehyde (4\%) for histological study.

\section{Paraffin tissue section}

Fixed testes were dehydrated in graded concentrations of ethanol (70\%, 80\%, 90\%, 95\%, and 100\%; Duksan, Korea) for 1 hour 30 minutes in each with gentle shaking and soaked in absolute ethanol overnight. The tissues were immersed in xylene (Samchun Chemical, Korea) for 30 minutes, 3 times and in paraffin (Avantik Biogroup, USA) at $56^{\circ} \mathrm{C}$ for 30 minutes, 3 times. The tissues were embedded in paraffin and sectioned (Microm, Germany) at $5 \mu \mathrm{m}$. The samples were attached on microscope slides (Marienfeld, Germany) and the slides were stained with hematoxylin (Sigma, USA) and eosin (Across, USA) for 5 minutes, respectively.

\section{Statistical analysis}

Values were expressed as mean \pm SE Data were analyzed using Student's $t$-test as indicated. $p<0.05$ was considered statistically significant. Calculations were performed using Graphpad Software Prism version 6.

\section{RESULTS}

\section{Changes in body weights}

In order to evaluate the effect of chronic low-dose expo- 
sure to NP on the weight gain of F1 male mice, we measured and compared the body weights at weaning day (PND 21) and at sacrifice day (PND 55) (Table 1). The initial body weights of the NP-50 group animals were significantly lower than those of control group animals $(p<0.05)$. Likewise, the terminal body weights of the NP-50 group animals were significantly lower than those of control group animals $(p<0.05)$. However, the weight gains were not significantly different between two groups.

\section{Changes in AGD index}

Table 2 indicates that there was no statically significant difference in the AGD indices between control and NPtreated male mice from PND 35 to PND 55.

\section{Changes in reproductive tissue weights}

As shown in Table 3, chronic low-dose NP exposure induced a significant increase in the absolute weight of the testes $(p<0.05)$. Conversely, the NP exposure caused significant decrease in the absolute weights of the epididymis $(p<0.01)$, prostate $(p<0.05)$ and seminal vesicle $(p<0.05)$ compared to the levels of control animals. However, the relative tissue weights were not significantly different between two groups.

Table 1. Effect of subchronic low-dose exposure to NP on the body weight gain from PND 21 to PND 55 in $\mathbf{F} 1$ male mice

\begin{tabular}{lcc}
\hline \hline & CON & NP-50 \\
\hline Initial body weight $(\mathrm{g})$ & $11.5 \pm 0.3$ & $10.2 \pm 0.5^{*}$ \\
Terminal body weight (g) & $30.3 \pm 0.5$ & $28.7 \pm 0.5^{*}$ \\
Increasing body weight (\%) & $260 \pm 4$ & $285 \pm 13$ \\
\hline
\end{tabular}

Values are expressed as mean $\pm \operatorname{SE}(n=9)$.

${ }^{*} p<0.05$, significantly different from the control group. CON, control group provided with tap water only; PND, postnatal day; NP-50, treated with nonylphenol at a dose of $50 \mu \mathrm{g} / \mathrm{L}$.

\section{Histopathological changes in testis and epididyimis}

In the control testis, normal cellular architectures of seminiferous tubule were observed; tight Sertoli-Germ cell junctions were evident and spermatids were abundant in the lumens (Fig. 1. CON). On the other hand, the volume of seminiferous tubule and its diameter, thickness of the basement membrane, luminal area and number of germ cell were decreased in the NP-treated testis (Fig. 1. NP50). Also, some sloughing morphologies were observed in the NP-treated testis. Numerous mature sperms were found in the caudal epididymis of control animal (Fig. 2. CON). On the contrary, fewer mature sperms were found in the caudal epididymis of NP-treated animal (Fig. 2. NP-50). Notably, swollen epithelial cells were found in NP-50 group showing irregular cell arrangement.

\section{DISCUSSION}

The estrogenic potential of NP in mammals has been well established since early 1990s (Soto et al., 1991). Concerning endocrine disturbing activities of NP, rodent studies clearly demonstrated and suggested that NP could inter-

Table 2. Effect of subchronic low-dose exposure to NP on changes in anogenital distance from PND 35 to PND 55 in F1 male mice

\begin{tabular}{cccc}
\hline \hline & PND & CON & NP-50 \\
\hline & 35 & $18.6 \pm 0.38$ & $18.3 \pm 0.33$ \\
$\begin{array}{c}\text { Anogenital } \\
\text { distance } \\
(\text { mm })\end{array}$ & 40 & $19.4 \pm 0.32$ & $19.4 \pm 0.24$ \\
& 50 & $20.1 \pm 0.29$ & $20.1 \pm 0.20$ \\
& 55 & $21.4 \pm 0.15$ & $21.4 \pm 0.12$ \\
\hline
\end{tabular}

Values are expressed as mean \pm SE $(n=9)$.

NP, nonylphenol; PND, postnatal day; CON, control group provided with tap water only NP-50, treated with nonylphenol at a dose of $50 \mu \mathrm{g} / \mathrm{L}$. 
Table 3. Effect of subchronic low-dose exposure to NP on the absolute and relative weights of reproductive organs in F1 male mice

\begin{tabular}{ccc}
\hline & CON & NP-50 \\
\hline Testis (mg, pair) & $98.55 \pm 1.97$ & $104.6 \pm 1.88^{*}$ \\
Testis (mg, pair)/body weight (g) & $3.26 \pm 0.14$ & $3.61 \pm 0.08$ \\
Epididymis (mg) & $44.40 \pm 0.80$ & $37.64 \pm 1.02^{* * *}$ \\
Epididymis/body weight (g) & $1.46 \pm 0.07$ & $1.43 \pm 0.09$ \\
Seminal vesicle (mg) & $58.97 \pm 2.15$ & $53.25 \pm 1.38^{*}$ \\
Seminal vesicle/body weight (g) & $1.87 \pm 0.10$ & $1.84 \pm 0.05$ \\
Prostate (mg) & $8.10 \pm 0.48$ & $6.62 \pm 0.4^{*}$ \\
Prostate (mg)/body weight (g) & $0.25 \pm 0.02$ & $0.23 \pm 0.01$ \\
\hline
\end{tabular}

Values are expressed as mean $\pm \mathrm{SE}(\mathrm{n}=9)$.

${ }^{*} p<0.05 ;{ }^{* * *} p<0.001$, significantly different from the control group value by $t$-test.

$\mathrm{CON}$, control group provided with tap water only; NP-50, treated with nonylphenol at a dose of $50 \mu \mathrm{g} / \mathrm{L}$.

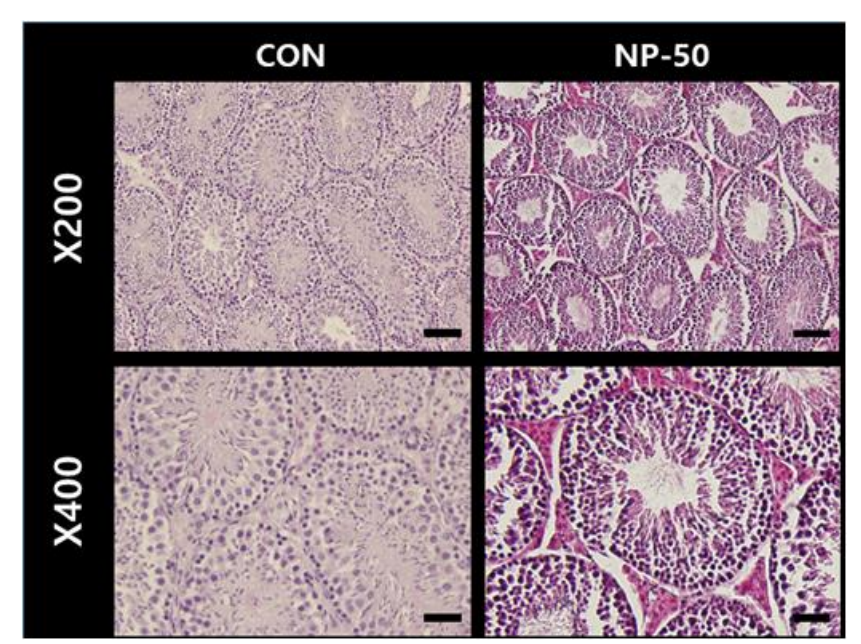

Fig. 1. Microphotographs of F1 testis. The paraffin-embedded tissues were sectioned at $5 \mu \mathrm{m}$ and the sections were stained with hematoxylin and eosin. In the control group, the normal sizes of seminiferous tubules and lumen and normal arrangement of normal arrangement of germ cells were observed. In the NP-treated group, the diameters of seminiferous tubules and lumen were decreased. Note that sloughing morphologies of NP-treated group. CON, control group provided with tap water only; NP-50, treated with NP at a dose of $50 \mu \mathrm{g} / \mathrm{L}$. Scale bar $(\times 200)=40 \mu \mathrm{m} ;(\times 400)=20 \mu \mathrm{m}$. NP, nonylphenol.

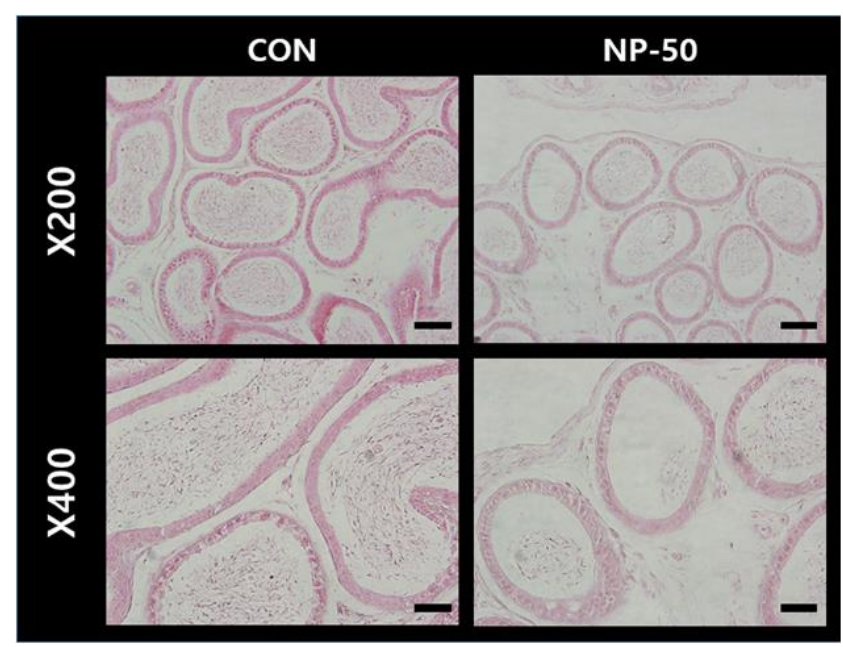

Fig. 2. Microphotographs of F1 caudal epididymis. The paraffin-embedded tissues were sectioned at $5 \mu \mathrm{m}$ and the sections were stained with hematoxylin and eosin. Numerous mature sperms were found in the caudal epididymis of control animal (CON). On the contrary, fewer mature sperms were found in the caudal epididymis of NP-treated animal (NP-50). Note that swollen epithelial cells were found in NP-50 group. CON, control group given tap water only; NP-50, treated with NP at a dose of $50 \mu \mathrm{g} / \mathrm{L}$. Scale bar $(\times 200)=40 \mu \mathrm{m} ;(\times 400)=20 \mu \mathrm{m}$. NP, nonylphenol. 
fere with both male and female reproductive system $(\mathrm{Na}-$ gao et al., 2001; Gong et al., 2009; Sato et al., 2009; Duan et al., 2016; Di et al., 2018). More specifically, ample evidence has been accumulated confirming the adverse effects of NP on the testis and epididymis. Exposure to paranonylphenol (p-NP, $250 \mathrm{mg} / \mathrm{kg} /$ day, oral administraion) resulted in significant decreases of the weight and volume of testis, volume of seminiferous tubules and its diameter, thickness of the basement membrane, height of the germinal epithelium, total number of types A and B spermatogonia, spermatocyte, spermatid and Sertoli cells in rat (Mehranjani et al., 2009). Another study with Sertoli cells and serum reproductive hormones in prepubertal male rats, both in vitro and in vivo, showed that NP could disrupt the structure and function of Sertoli cells in vitro and hormone levels in serum even at low doses (Hu et al., 2014). The $\mathrm{NP}(60 \mathrm{mg} / \mathrm{kg})$-induced apoptosis, autophagy and necrosis in Sertoli cell seem to be through ROS-mediated pathway (Duan et al., 2016). Exposure of epididymal rat sperm to NP (250-500 ug/mL) significantly reduced motility, acrosomal integrity and acrosomal reaction (Uguz et al., 2009). Absolute testes and epididymides weights, sperm counts in cauda and caput/corpus epididymides, sperm motility, daily sperm production and sperm transit time in cauda epididymis were significantly decreased in rats gavaged with NP (100-300 mg/kg/day, for 30days) (Aly et al., 2012). Oral administration of NP (250 mg/kg/day for 90days) may damage the structure and function of testis, induce apoptosis and oxidative stress in epididymis or even have cytotoxic effects on epididymal sperm ( $\mathrm{Lu}$ et al., 2014). In the present study, we found that the decreases of absolute weights in the accessory sex organs and the histopathological changes in testis and epididymis of low-dose NP treated mice, shown good agreement with the detrimental effects of NP exposure in previous reports. In particular, NP exposure with very low dose which is reflecting human daily intake level could elicit similar detrimental effects in the previous studies mostly adopted high-dose models. The multiple 'sloughing morphology', defined as a separation of at least one germ cell layer from the seminiferous epithelium, was observed in our testis sections from NP-treated animals, indicating the impaired spermatogenesis. Also, apparent reduction in sperm number from NP-treated epididymis in the present study could be closely related to the sperm count decrease in NP-treated animals (Chitra et al., 2002; Uguz et al., 2009; Aly et al., 2012).

NP and its metabolites are found in several human tissues and biological fluids such as adipose tissues, liver, amniotic fluid, breast milk, urine and semen (Muncke, 2009; Huang et al., 2016; Acir \& Guenther, 2018). For example, the maximum NP concentration in adipose tissue was $85 \mathrm{ng} / \mathrm{g}$ lipids (Muller et al., 1998). Since the presence of NPs in human tissues was evident, it is certainly plausible that human exposure to NP could induce reproductive toxicity as found in rodent studies. However, to obtain practical information on the adverse effect of NP on human physiology, low-dose exposure issue must be carefully considered. The initially proposed no-observed-adverseeffect level (NOAEL) of NP in rat was $50 \mathrm{mg} / \mathrm{kg} /$ day (Cunny et al., 1999; Fourie et al., 2001). Recently, using mathematical models, the NOAEL of NP was revised to 15 $\mathrm{mg} / \mathrm{kg} /$ day (Mao et al., 2019). Therefore, doses higher than NOAEL have been used in mostly all of laboratory animal researches, and such high-dose exposure is not likely to happen in our everyday lives. Based on an analysis of 60 different foodstuffs and food consumption rates in Germany, the average daily human intake of NP was calculated to be $7.5 \mathrm{ug} / \mathrm{day}$, and for infants exclusively fed with breast milk or infant formulas, daily intakes are estimated to 0.2 and $1.4 \mathrm{ug} /$ day, respectively (Guenther et al., 2002). In the present study, estimated daily intake of NP was $18.5-19.8$ $\mathrm{ug} / \mathrm{kg} /$ day when body weight was about $30 \mathrm{~g}$. This level was about 1,000 times lower than currently accepted NOAEL for rat, and we thought our low-dose NP exposure model was much closer to the daily human intake.

Low-dose effects were defined by the National Toxicol- 
ogy Program (NTP) as those that occur in the range of human exposures or effects observed at doses below those used for traditional toxicological studies (Vandenberg et al., 2012). Actually, there is growing evidence to support low-dose effects of NP (Melnick et a., 2002; Di et al., 2018; Patino-Garcia et al., 2018; Yu et al., 2018). Nonmonotonic dose-response curves, a nonlinear relationship between dose and effect where the slope of the curve changes sign somewhere within the range of doses examined, is best explanation for the low-dose (i.e. nanomolar concentration) effects of EDCs including NP so far (Vandenberg et al., 2012).

The present study demonstrated that exposure to subchronic low-dose NP induced abnormality of reproductive organs in male F1 mice. Since the NP dose used in this study is closely related to the average human daily NP exposure, our results could have profound meaning, a serious alert on the male infertility (de Jager et al., 1999).

\section{ACKNOWLEDGMENTS}

This work was supported by the National Research Foundation of Korea (NRF) grant funded by the Korea Government (2011-0025490).

\section{REFERENCES}

Acir IH, Guenther K (2018) Endocrine-disrupting metabolites of alkylphenol ethoxylates: A critical review of analytical methods, environmental occurrences, toxicity, and regulation. Sci Total Environ 635:1530-1546.

Aly HA, Domenech O, Banjar ZM (2012) Effect of nonylphenol on male reproduction: Analysis of rat epididymal biochemical markers and antioxidant defense enzymes. Toxicol Appl Pharmacol 261:134-141.

Cha S, Baek JW, Ji HJ, Choi JH, Kim C, Lee MY, Hwang YJ, Yang E, Lee SH, Jung HI, Cheon YP (2017) Disturbing effects of chronic low-dose 4-nonylphenol ex- posing on gonadal weight and reproductive outcome over one-generation. Dev Reprod 21:121-130.

Chitra KC, Latchoumycandane C, Mathur PP (2002) Effect of nonylphenol on the antioxidant system in epididymal sperm of rats. Arch Toxicol 76:545-551.

Cunny HC, Mayes BA, Rosica KA, Trutter JA, Van Miller JP (1999) Subchronic toxicity (90-day) study with para-nonylphenol in rats. Regul Toxicol Pharmacol 26: 72-178.

de Jager C, Bornman MS, van der Horst G (1999) The effect of p-nonylphenol, an environmental toxicant with oestrogenic properties, on fertility potential in adult male rats. Andrologia 31:99-106.

de Weert J, de la Cal A, van den Berg H, Murk A, Langenhoff A, Rijnaarts H, Grotenhuis T (2008) Bioavailability and biodegradation of nonylphenol in sediment determined with chemical and bioanalysis. Environ Toxicol Chem 27:778-785.

Di QN, Cao WX, Xu R, Lu L, Xu Q, Wang XB (2018) Chronic low-dose exposure of nonylphenol alters energy homeostasis in the reproductive system of female rats. Toxicol Appl Pharmacol 348:67-75.

Duan P, Hu C, Butler HJ, Quan C, Chen W, Huang W, Tang S, Zhou W, Yuan M, Shi Y, Martin FL, Yang K (2016) Effects of 4-nonylphenol on spermatogenesis and induction of testicular apoptosis through oxidative stress-related pathways. Reprod Toxicol 62:27-38.

Fourie MH, Bornman MS, Viljoen E (2001) Epididymal markers in rats exposed to the xenoestrogen p-nonylphenol: No biochemical effects at low dosages. Andrologia 33:305-310.

Gong Y, Wu J, Huang Y, Shen S, Han X (2009) Nonylphenol induces apoptosis in rat testicular Sertoli cells via endoplasmic reticulum stress. Toxicol Lett 186:84-95.

Guenther K, Heinke V, Thiele B, Kleist E, Prast H, Raecker T (2002) Endocrine disrupting nonylphenols are ubiquitous in food. Environ Sci Technol 36:1676-1680.

Hu Y, Wang R, Xiang Z, Qian W, Han X, Li D (2014) An- 
tagonistic effects of a mixture of low-dose nonylphenol and di-n-butyl phthalate (monobutyl phthalate) on the Sertoli cells and serum reproductive hormones in prepubertal male rats in vitro and in vivo. PLOS ONE 9:e93425.

Huang SL, Tuan NN, Lee K (2016) Occurrence, human intake and biodegradation of estrogen-like nonylphenols and octylphenols. Curr Drug Metab 17:293-302.

Kyselova V, Peknicova J, Buckiova D, Boubelik M (2003) Effects of p-nonylphenol and resveratrol on body and organ weight and in vivo fertility of outbred CD-1 mice. Reprod Biol Endocrinol 1:30.

Lu WC, Wang AQ, Chen XL, Yang G, Lin Y, Chen YO, Hong CJ, Tian HL (2014) 90d Exposure to nonylphenol has adverse effects on the spermatogenesis and sperm maturation of adult male rats. Biomed Environ Sci 27:907-911.

Mao W, Song Y, Sui H, Cao P, Liu Z (2019) Analysis of individual and combined estrogenic effects of bisphenol, nonylphenol and diethylstilbestrol in immature rats with mathematical models. Environ Health Prev Med. 24:32.

Mehranjani MS, Noorafshan A, Momeni HR, Abnosi MH, Mahmoodi M, Anvari M, Hoseini SM (2009) Stereological study of the effects of vitamin $\mathrm{E}$ on testis structure in rats treated with para-nonylphenol. Asian J Androl 11:508-516.

Melnick R, Lucier G, Wolfe M, Hall R, Stancel G, Prins G, Gallo M, Reuhl K, Ho SM, Brown T, Moore J, Leakey J, Haseman J, Kohn M (2002) Summary of the National Toxicology Program's report of the endocrine disruptors low-dose peer review. Environ Health Perspect 110:427-431.

Muller S, Schmid P, Schlatter C (1998) Pharmacokinetic behavior of 4-nonylphenol in humans. Environ Toxicol Pharmacol 5:257-265.

Muncke J (2009) Exposure to endocrine disrupting compounds via the food chain: Is packaging a relevant source? Sci Total Environ 407:4549-4559.
Nagao T, Wada K, Marumo H, Yoshimura S, Ono H (2001) Reproductive effects of nonylphenol in rats after gavage administration: A two-generation study. Reprod Toxicol 15:293-315.

Noorimotlagh Z, Haghighi NJ, Ahmadimoghadam M, Rahim F (2017) An updated systematic review on the possible effect of nonylphenol on male fertility. Environ Sci Pollut Res Int 24:3298-3314.

Noorimotlagh Z, Mirzaee SA, Ahmadi M, Jaafarzadeh N, Rahim F (2018) The possible DNA damage induced by environmental organic compounds: The case of nonylphenol. Ecotoxicol Environ Saf 158:171-181.

Patino-Garcia D, Cruz-Fernandes L, Bunay J, Palomino J, Moreno RD (2018) Reproductive alterations in chronically exposed female mice to environmentally relevant doses of a mixture of phthalates and alkylphenols. Endocrinology 159:1050-1061.

Sato T, Saito H, Uchiyama T, Fujimoto Y, Katase T, Kai O (2009) Effects of synthetic para-nonylphenol isomers administered chronically throughout pregnancy and lactation on reproductive system of mouse pups. Arch Toxicol 83:1097-1108.

Soto AM, Justicia H, Wray JW, Sonnenschein C (1991) pNonyl-phenol: An estrogenic xenobiotic released from "modified" polystyrene. Environ Health Perspect 92: 167-173.

Uguz C, Varisli O, Agca C, Agca Y (2009) Effects of nonylphenol on motility and subcellular elements of epididymal rat sperm. Reprod Toxicol 28:542-549.

Vandenberg LN, Colborn T, Hayes TB, Heindel JJ, Jacobs DR Jr, Lee DH, Shioda T, Soto AM, vom Saal FS, Welshons WV, Zoeller RT, Myers JP (2012) Hormones and endocrine-disrupting chemicals: Low-dose effects and nonmonotonic dose responses. Endocr Rev 33:378-455.

Yu J, Yang J, Luo Y, Mengxue Y, Li W, Yang Y, He L, Xu J (2018) The adverse effects of chronic low-dose exposure to nonylphenol on type 2 diabetes mellitus in high sucrose-high fat diet-treated rats. Islets 10:1-9. 